NISTIR 6886

\title{
Influence of Curing Conditions on Water Loss and Hydration in Cement Pastes with and without Fly Ash Substitution
}

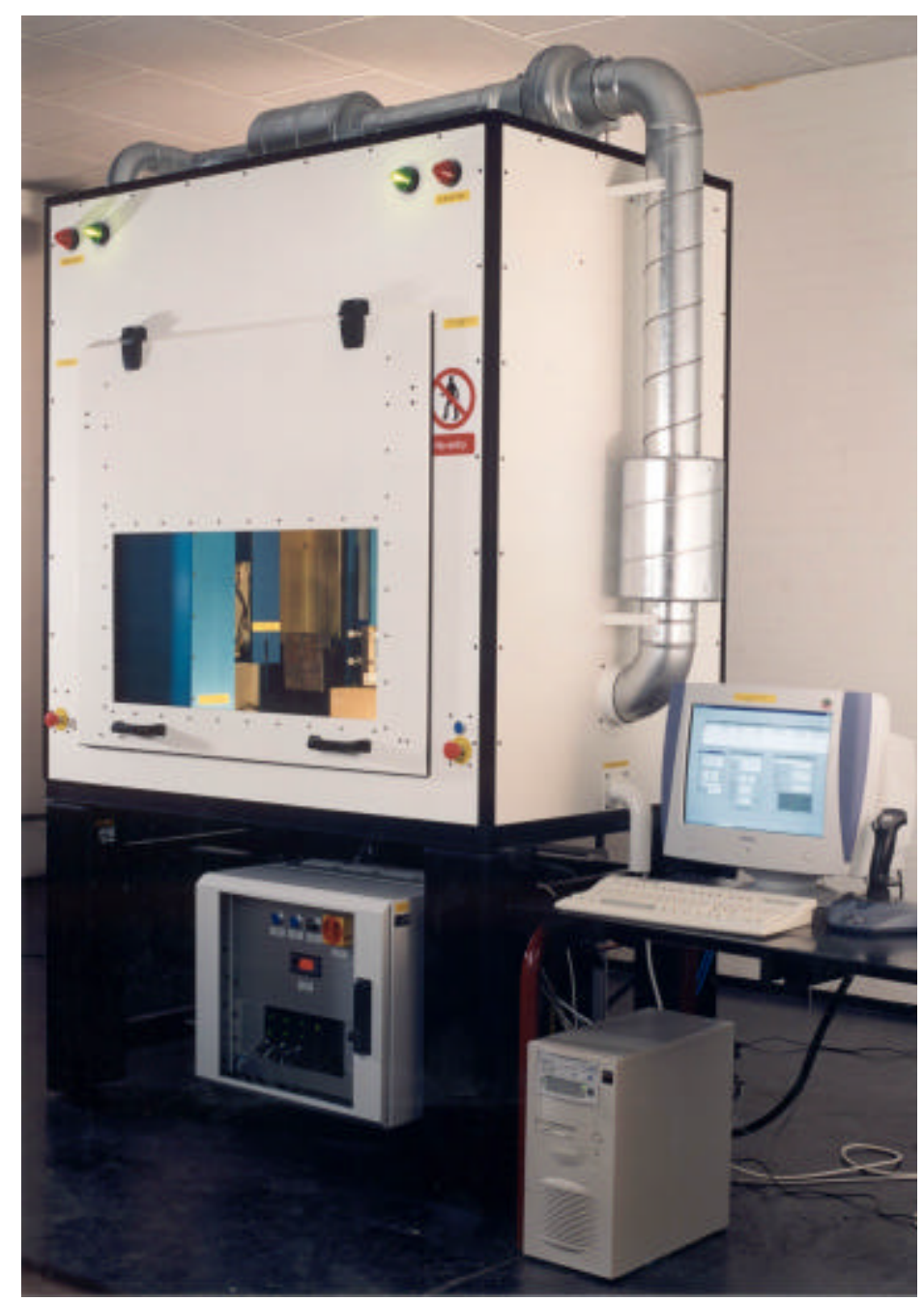

Dale P. Bentz

National Institute of Standards and Technology Technology Administration, U.S. Department of Commerce 
NISTIR 6886

\section{Influence of Curing Conditions on Water Loss and Hydration in Cement Pastes with and without Fly Ash Substitution}

Dale P. Bentz

Building and Fire Research Laboratory

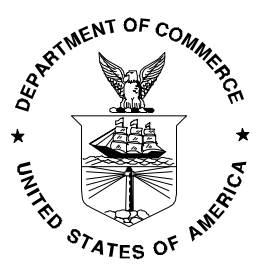

U.S. Department of Commerce

Donald L. Evans, Secretary

Technology Administration Phillip J. Bond, Under Secretary for Technology 


\begin{abstract}
The proper curing of concrete is paramount to achieving desired strength and durability performance in the field. Because blending components often react at different rates from portland cement, blended cements may require that special attention be paid to prolonged curing. This report summarizes an exploratory study on the influence of curing conditions on water loss and hydration in ASTM Type I and blended portland cement pastes with a water-cementitious materials ratio $(\mathrm{w} / \mathrm{cm})$ of 0.40 . The blended cement contains about $20 \%$ by mass fly ash substitution for cement. Water loss/gain under various curing conditions is monitored both globally by bulk mass (loss) measurements and locally using the NIST X-ray absorption apparatus. Hydration is assessed based on the measurement of non-evaporable water content after $31 \mathrm{~d}$ of curing. Curing conditions include no curing (exposed to the environment throughout the curing period), sealed curing, and saturated curing for $1 \mathrm{~d}, 3 \mathrm{~d}$, and $6 \mathrm{~d}$. The cement paste with the fly ash substitution is observed to be more sensitive to curing conditions than the conventional Type I portland cement paste.
\end{abstract}

Keywords: Building technology; cement paste; curing; fly ash; evaporation; hydration. 


\section{Contents}

Abstract __ iii

List of Figures __ v

List of Tables ___ vi

1 Introduction

2 Experimental 22

3 Results

4 Discussion _ 13

5 Summary and Conclusions _ 13

6 Acknowledgements 


\section{List of Figures}

Figure 1. SEM/X-ray composite image of the ASTM Type I portland cement.

Figure 2. SEM/X-ray composite image of the blended cement containing about $20 \%$ by

mass fly ash.

Figure 3. Relative water loss/gain vs. time for the cement pastes with and without fly ash exposed to various curing regimens.

Figure 4. X-ray profiles (differences in counts) for pastes without and with fly ash, immediately exposed to the drying environment in the X-ray chamber.

Figure 5. X-ray profiles (differences in counts) for pastes without and with fly ash, sealed throughout the curing period.

Figure 6. X-ray profiles (differences in counts) for pastes without and with fly ash, saturated for $1 \mathrm{~d}$ and then exposed to the chamber environment.

Figure 7. X-ray profiles for samples saturated for $3 \mathrm{~d}(72 \mathrm{~h})$ and then exposed to the chamber environment.

Figure 8. X-ray profiles for samples saturated for $6 \mathrm{~d}(144 \mathrm{~h})$ and then exposed to the chamber environment.

Figure 9. Evaporable water loss (g water/g ignited powder) for top and bottom sections of cement pastes without and with fly ash, exposed to various curing conditions. 11 Figure 10. Non-evaporable water loss (g water/g ignited powder) for top and bottom sections of cement pastes without and with fly ash. 


\section{List of Tables}

Table 1. Area fractions from SEM/X-ray analysis for the two cements. 3 


\section{Introduction}

For many construction projects, concrete is the material of choice. Concrete structures can be designed to be strong and durable in a variety of aggressive environments. In practice, proper curing (suitable temperature and moisture availability) is critical to achieving concrete that lives up to its intended functionality. ${ }^{1}$ Blended cement concretes may be particularly sensitive to curing conditions, as blending components such as fly ashes and slags may not react as rapidly as the base cement. In these cases, prolonged moist curing may be required to achieve full development of strength and durabilityrelated properties.

Proper curing is especially critical in achieving a discontinuous pore structure in concretes with water-cementitious materials ratios $(\mathrm{w} / \mathrm{cm})$ of 0.45 and lower. A discontinuous pore structure is important in producing a durable concrete, as it will limit both water and ion ingress into the interior of the concrete structure. Based on measurements of permeability, Powers concluded that capillary discontinuity is a function of both $\mathrm{w} / \mathrm{cm}$ and degree of hydration, with higher $\mathrm{w} / \mathrm{cm}$ requiring longer hydration times to achieve a discontinuous capillary pore structure. ${ }^{2}$ He therefore suggested curing the concrete only until this discontinuity is achieved, as further "saturated" curing would result in little if any further water flow into the concrete. ${ }^{3}$ Based on a microstructural model for cement paste hydration, Bentz and Garboczi suggested a critical capillary porosity threshold value of about $20 \%$ to achieve this discontinuity. ${ }^{4}$ For any starting w/cm ratio, if hydration can reduce the initial capillary porosity to $20 \%$ or so, a discontinuous pore structure will be formed.

In this paper, fundamental studies on water loss and hydration in small cement paste specimens (w/cm $=0.40$, with and without fly ash substitution) exposed to various curing conditions are presented. Water loss is monitored globally using bulk mass loss measurements and locally using the NIST X-ray absorption apparatus. The examined curing conditions include immediate exposure to the X-ray chamber environment (nominally at $23{ }^{\circ} \mathrm{C}$ and $55 \% \mathrm{RH}$ ), sealed curing for $31 \mathrm{~d}$, and saturated curing (with water on top) for $1 \mathrm{~d}, 3 \mathrm{~d}$, and $6 \mathrm{~d}$, followed in each case by exposure to the chamber environment. 


\section{Experimental}

Two cements supplied by a U.S. cement manufacturer were employed in this study. The first was an ASTM Type I portland cement (Blaine fineness of $343 \mathrm{~m}^{2} / \mathrm{kg}$ ) and the second was an interground mixture of the first cement with a class $\mathrm{F}$ fly ash to produce an IP blended cement (Blaine fineness of about $400 \mathrm{~m}^{2} / \mathrm{kg}$ ). Color-coded SEM/X-ray composite images of the two cements are provided in Figures 1 and 2. Volumetric phase fractions determined from the SEM/X-ray composite images are provided in Table 1. As would be expected, the volumetric composition of the IP cement (in terms of the four principal clinker compounds: $\mathrm{C}_{3} \mathrm{~S}, \mathrm{C}_{2} \mathrm{~S}, \mathrm{C}_{3} \mathrm{~A}$, and $\mathrm{C}_{4} \mathrm{AF}$ ) is dominated by that of the Type I portland cement that was interground with the fly ash to produce the blended product.

Cement pastes with a w/cm of 0.40 were prepared by mixing the cement powder and water together by hand in sealed plastic bags for two to three minutes. Freshly-mixed pastes were removed from the plastic bags and cast into small plastic "UV" cuvettes (10

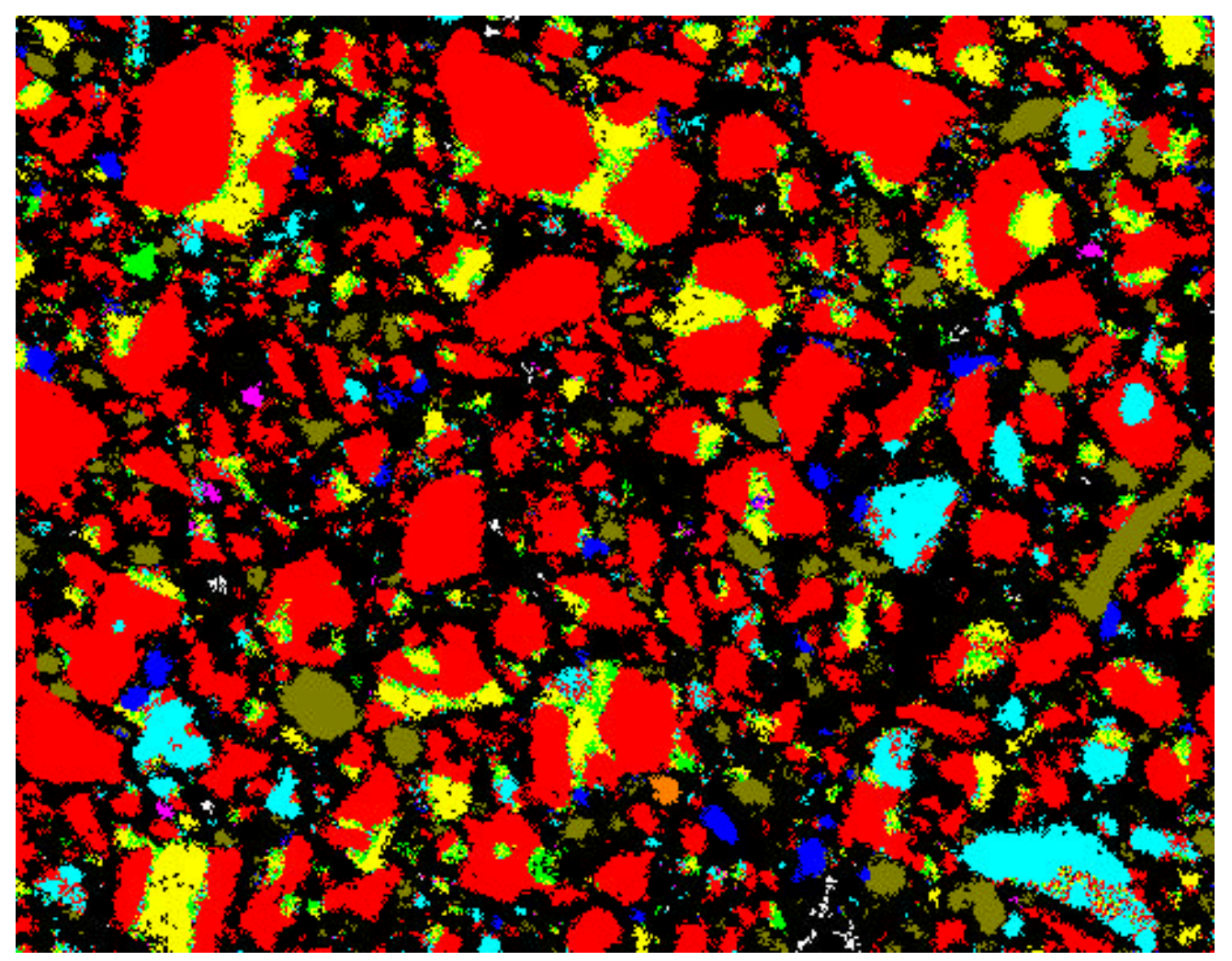

Figure 1. SEM/X-ray composite image of the ASTM Type I portland cement. Red is tricalcium silicate, aqua is dicalcium silicate, green is tricalcium aluminate, yellow is tetracalcium aluminoferrite, pale green is calcium sulfate, white is free lime, blue is potassium sulfate, and magenta is periclase. Image is 256 ìm x 200 ìm. 
Table 1. Area fractions from SEM/X-ray analysis for the two cements.

\begin{tabular}{|c|c|c|}
\hline \multirow{2}{*}{ Phase } & \multicolumn{2}{|c|}{ Area fraction } \\
\cline { 2 - 3 } & Type I cement & Type IP cement \\
\hline $\mathrm{C}_{3} \mathrm{~S}$ & 0.6266 & 0.4271 \\
\hline $\mathrm{C}_{2} \mathrm{~S}$ & 0.0910 & 0.0651 \\
\hline $\mathrm{C}_{3} \mathrm{~A}$ & 0.0727 & 0.0495 \\
\hline $\mathrm{C}_{4} \mathrm{AF}$ & 0.0794 & 0.0574 \\
\hline Calcium sulfate & 0.0759 & 0.0914 \\
\hline Free lime & 0.0076 & 0.0155 \\
\hline $\mathrm{K}_{2} \mathrm{SO}_{4}$ & 0.0134 & 0.0051 \\
\hline "Periclase" & 0.0080 & 0.0072 \\
\hline Silica & 0.0089 & 0.0771 \\
\hline Aluminosilicate & 0.0060 & 0.1849 \\
\hline CAS & 0.0105 & 0.0197 \\
\hline
\end{tabular}

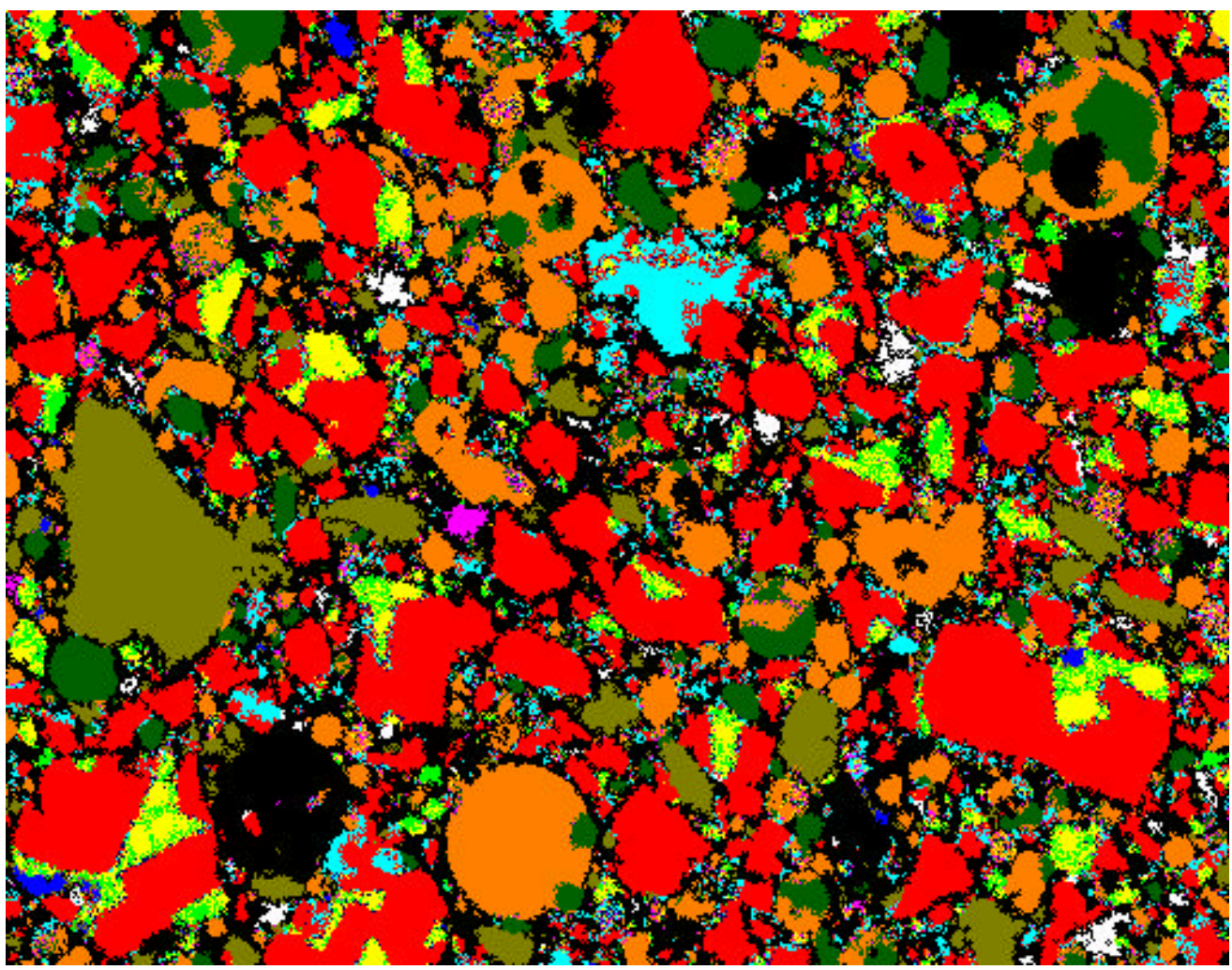

Figure 2. SEM/X-ray composite image of the blended cement containing about $20 \%$ by mass fly ash. Colors are as in Figure 1, but additionally, orange is an aluminosilicate (fly ash), dark green is silica (fly ash), and dark blue is calcium aluminosilicate (fly ash). $\mathrm{mm}$ by $10 \mathrm{~mm}$ by $40 \mathrm{~mm}$ ), each cuvette being mounted on a "Lego ${ }^{\mathrm{TM}}$ "1 block base plate using a two-component epoxy adhesive. The cuvettes could be conveniently sealed using small plastic caps to minimize mass loss during sealed curing and then mounted on a

${ }^{1}$ Certain commercial equipment is identified in this report to specify the experimental procedure. In no case does such identification imply endorsement by the National Institute of Standards and Technology, nor does it indicate that the equipment is necessarily the best available for the purpose. 
larger Lego base plate within the X-ray absorption chamber. These cuvette specimens were then exposed to different curing regimens with periodic measurements of the specimen masses and moisture distributions (via X-ray absorption). X-ray results will be presented for curing times of $4.5 \mathrm{~h}$ (approximately the time of setting), $6.5 \mathrm{~h}, 20 \mathrm{~h}, 73 \mathrm{~h}$, and $433 \mathrm{~h}$. For the current study, X-ray absorption measurements were performed at a spatial resolution of $1 \mathrm{~mm}$. Each cuvette was filled with cement paste to a height of approximately $30 \mathrm{~mm}$.

Details of the X-ray absorption apparatus and the monitoring of moisture distributions in hydrating cement pastes have been provided previously. ${ }^{5,6,7}$ At each spatial position and time, each measured spectra was characterized by the sum of the counts for the X-rays transmitted through the specimen, in all 256 energy-level channels of the spectra. As the cement paste specimen loses moisture locally at some depth, the X-ray "counts" transmitted through the specimen at that depth will increase. The counts obtained after any specific curing time are first proportionally normalized via a specimen of dry cement powder, to account for any minor variations in the X-ray source intensity between experimental runs. The normalized counts are then referenced (by differencing) to those achieved near the setting time (about $4.5 \mathrm{~h}$ ) to infer the change in moisture distribution for the specimen. ${ }^{6}$ The "differences in counts" between a specimen at some later age and the same specimen at its setting time will be positive when a water loss has occurred (decrease in density allowing a greater transmission of the X-rays) and negative when water ingress has occurred. Previously, measurements have indicated that moisture contents (by mass) of porous materials can be determined with a coefficient of variation of $6 \%$ using the X-ray absorption technique. ${ }^{5}$

The following five curing conditions were investigated in this study:

a) exposed to the environment of the X-ray chamber

b) sealed with a plastic cap

c) saturated on top for $\mathbf{1} \mathbf{d}$ then exposed to the chamber environment

d) saturated on top for $\mathbf{3} \mathbf{d}$ then exposed to the chamber environment

e) saturated on top for $\mathbf{6} \mathbf{d}$ then exposed to the chamber environment.

With 5 curing conditions and 2 mixtures (with and without fly ash), 10 cuvette specimens in total were prepared. After $31 \mathrm{~d}$ of hydration, the cuvettes were removed from the X-ray absorption chamber, the specimens were "extruded" from the cuvettes and the top $10 \mathrm{~mm}$ of each cement paste prism specimen was removed by notching the specimen on two opposite sides using a hacksaw and then using a hammer and chisel to break the specimen in two. Loss on ignition measurements were used to determine the evaporable (mass loss on heating to $105^{\circ} \mathrm{C}$ ) and non-evaporable (subsequent mass loss on heating to $1000{ }^{\circ} \mathrm{C}$ ) water contents of the top $10 \mathrm{~mm}$ and the remaining bottom section (about 20 $\mathrm{mm}$ in height) of each of the 10 cement paste specimens. Based on the expected uncertainty of the mass measurements involved in determining the evaporable and nonevaporable water contents $(0.001 \mathrm{~g})$, a typical expanded uncertainty ${ }^{8}$ in the calculated water contents is estimated to be $0.001 \mathrm{~g}$ of water/( $\mathrm{g}$ of ignited powder), assuming a coverage factor ${ }^{8}$ of $2 .{ }^{9}$ 


\section{$3 \quad$ Results}

The relative mass losses/gains in water from the paste specimens based on bulk mass measurements are provided in Figure 3. The specimens exposed to saturated curing, followed by drying, first gain mass (a negative water change), losing water only when exposed to subsequent drying. The initial mass gain is due to water imbibition through the top saturated surface of the specimen to replace the water "lost" internally due to chemical shrinkage during cement hydration. ${ }^{9,10}$ For similar curing regimens, the specimens with the fly ash substitution for cement are observed to consistently lose more water than those without, indicating a possible increased sensitivity to curing for the blended cement.

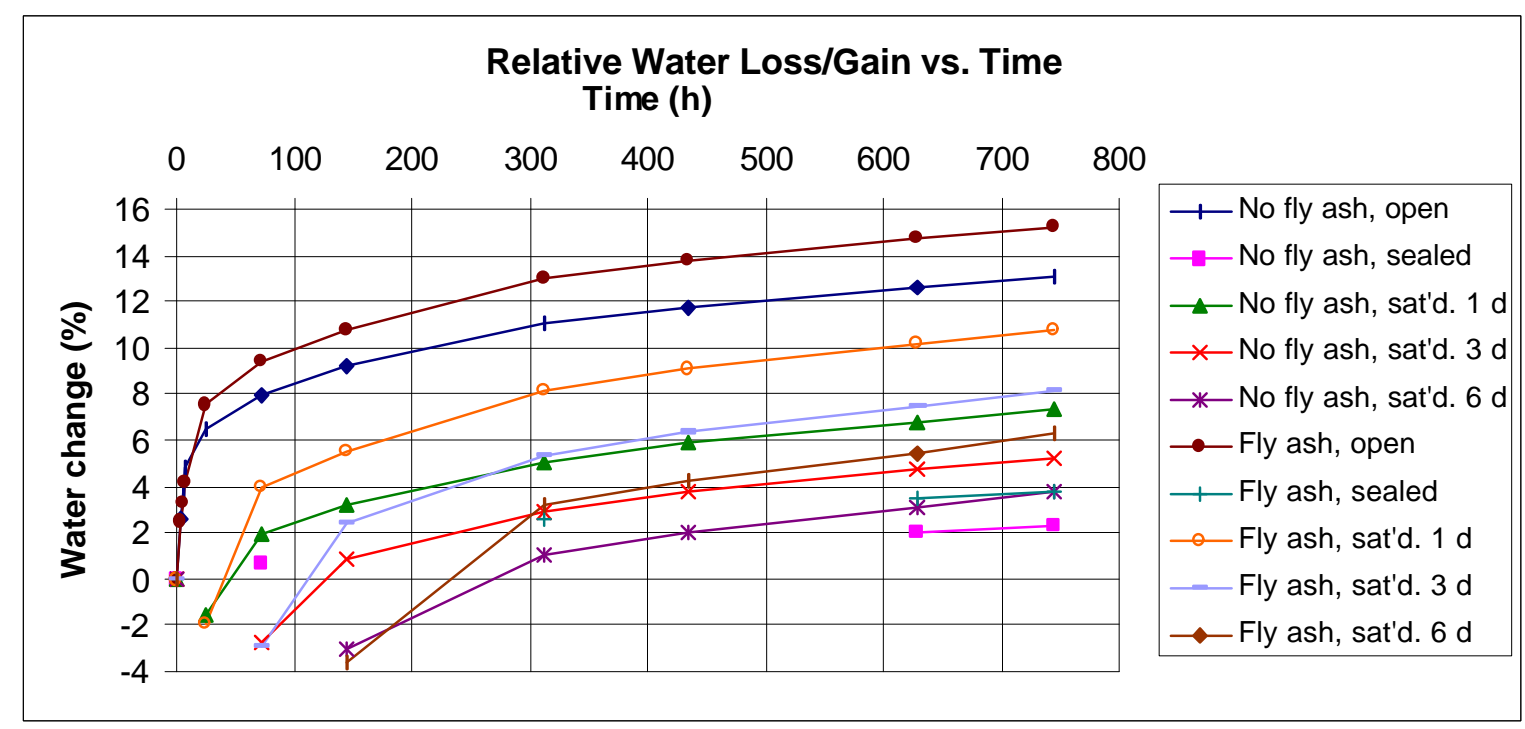

Figure 3. Relative water loss/gain vs. time for the cement pastes with and without fly ash exposed to various curing regimens. Positive values indicate a mass loss and negative values a mass gain (due to water imbibition).

These results are supported by the X-ray counts difference profiles shown in Figures 4 through 8 , for each of the five different curing conditions. For the specimens immediately exposed to the chamber environment (Figure 4), a significantly greater water loss (higher difference in counts) and a deeper penetration of the drying front (28 $\mathrm{mm}$ vs. $20 \mathrm{~mm}$ ) is observed after $18 \mathrm{~d}$ of drying for the specimen containing fly ash. The drying front penetration depth for each specimen is visually estimated as the depth where there is a discontinuous change in the "differences in counts" profile.

For the sealed conditions, as indicated in Figure 3, a small mass loss occurred for both specimens ( $2 \%$ to $4 \%$ after 700 h of curing). Here, the X-ray profiles shown in Figure 5 indicate a small and relatively uniform moisture loss throughout the specimen thickness for both the pastes without and with fly ash. But, once again, a greater water loss is indicated for the system containing the fly ash substitution (higher differences in counts). 
The benefits of saturated curing can be observed in Figures 6 to 8, where in each case, water loss from the small specimens is basically prevented as long as the saturated conditions are maintained. In fact, during this saturated "curing time", water imbibition
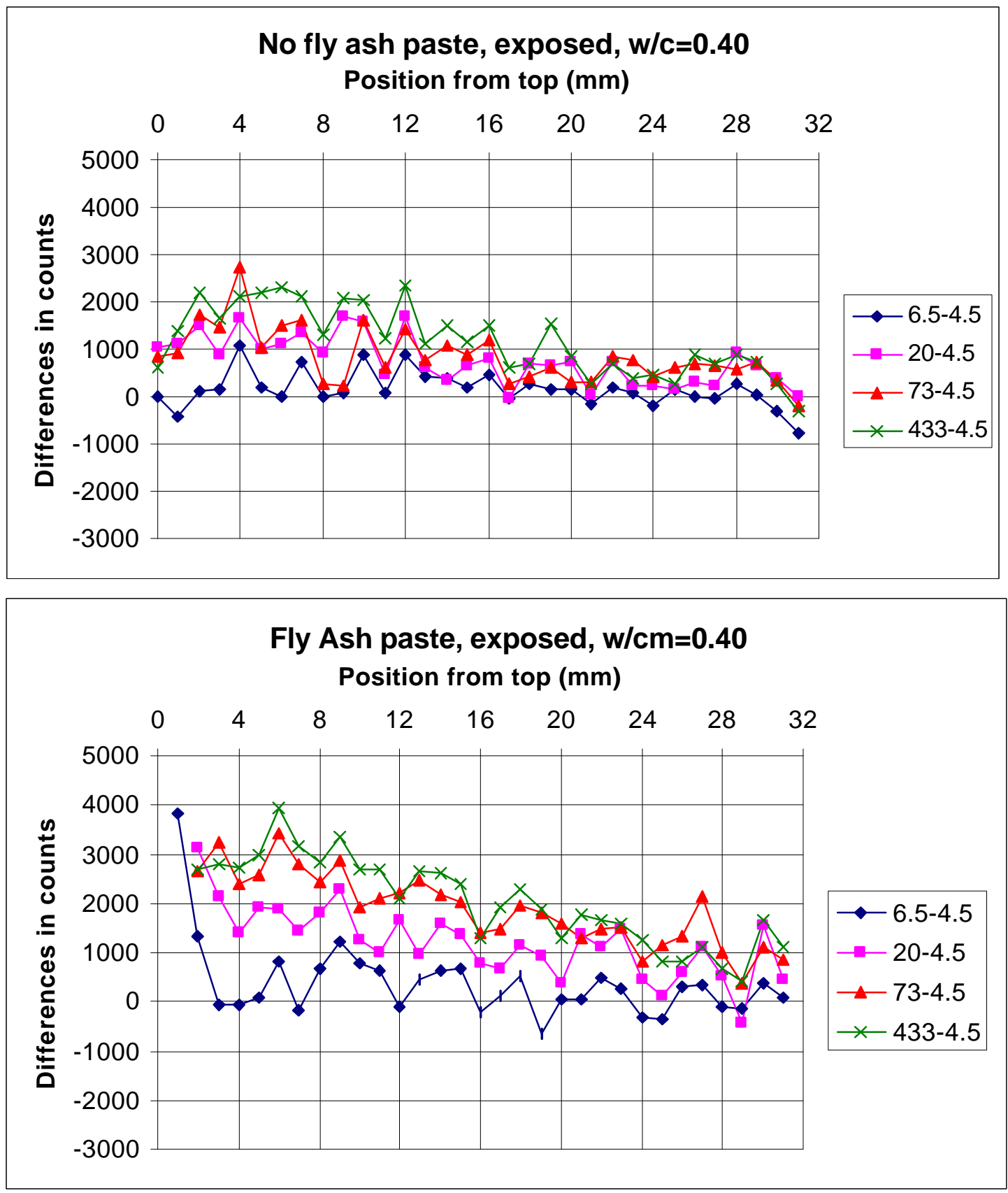

Figure 4. X-ray profiles (differences in counts) for pastes without and with fly ash, immediately exposed to the drying environment in the X-ray chamber. All differences $(6.5 \mathrm{~h}, 20 \mathrm{~h}, 73 \mathrm{~h}$, and $433 \mathrm{~h})$ are relative to counts obtained for the $4.5 \mathrm{~h}$ specimens as indicated in the legend box. Positive values indicate a local water loss and negative values indicate a local water gain. The top (exposed surface) of the specimen is at position 0 and the bottom at position 32 . 
into the specimens is indicated both by the bulk mass measurements in Figure 3 and by the slight negative differences in counts commonly observed for the earliest ages in Figures 6 to 8. For the specimens saturated for their first day of curing (Figure 6), the depth of the drying front after $17 \mathrm{~d}$ of drying is about $12 \mathrm{~mm}$ for the paste without fly ash and $20 \mathrm{~mm}$ for the paste with fly ash. For the specimens saturated for their first three days of curing (Figure 7), the depth of the drying front after $15 \mathrm{~d}$ of drying is only a few


Figure 5. X-ray profiles (differences in counts) for pastes without and with fly ash, sealed throughout the curing period. All differences are relative to counts obtained for the $4.5 \mathrm{~h}$ specimens. 
$\mathrm{mm}$ for the paste without fly ash and about $10 \mathrm{~mm}$ for the paste with fly ash. For the $6 \mathrm{~d}$ specimens (Figure 8), this depth is nearly non-existent for the paste without fly ash and about $5 \mathrm{~mm}$ for the paste with fly ash. In each case, the paste specimens with fly ash substitution for cement are indeed observed to be more sensitive to curing, both in terms of an increase in water mass loss and in terms of the greater depth of the "drying front."
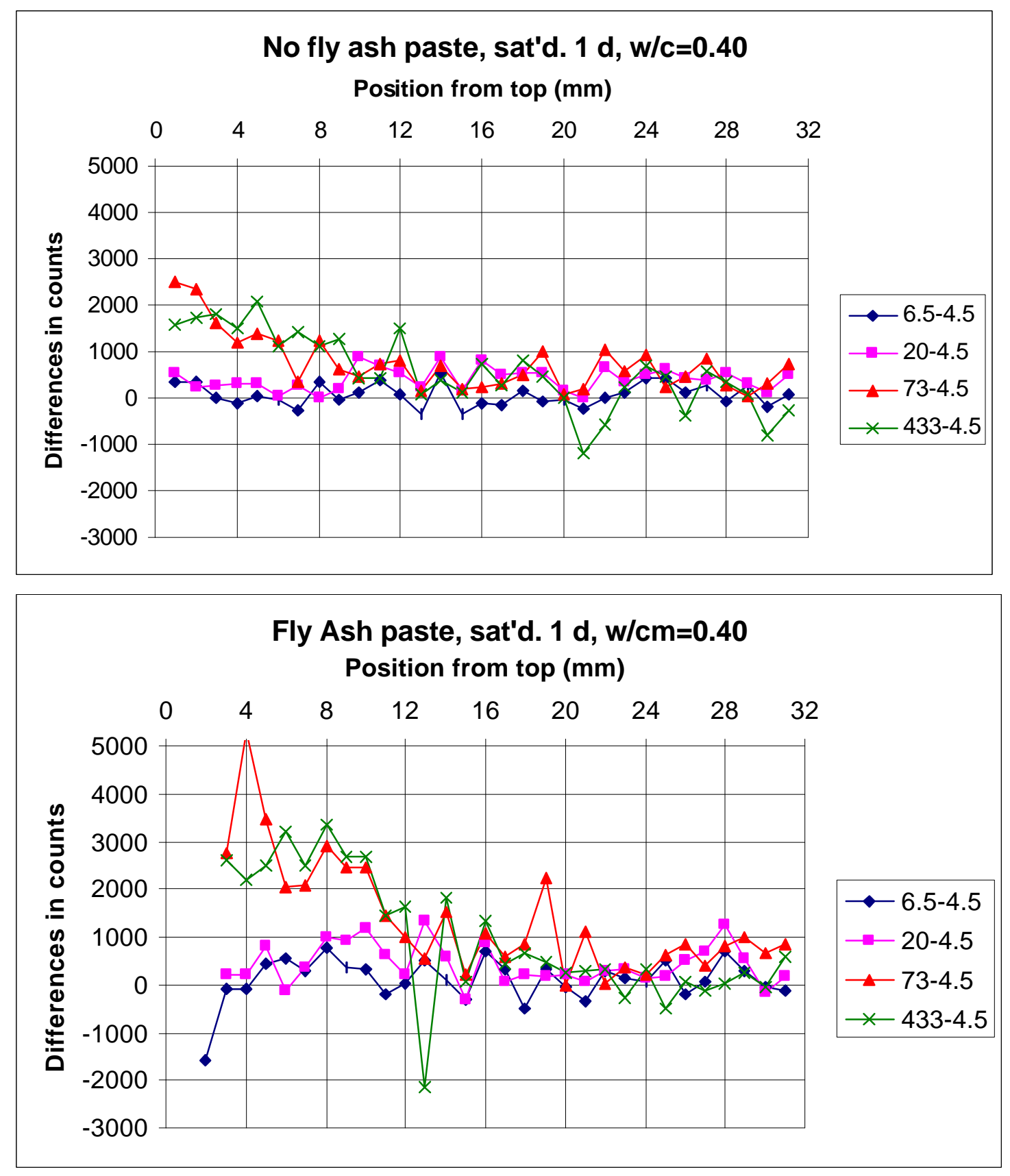

Figure 6. X-ray profiles (differences in counts) for pastes without and with fly ash, saturated for $1 \mathrm{~d}$ and then exposed to the chamber environment. All differences are relative to counts obtained for the $4.5 \mathrm{~h}$ specimens. 
Further insight into the early hydration behavior and moisture content of the specimens exposed to the various curing conditions is provided by measurement of the evaporable and non-evaporable water contents after a total of $31 \mathrm{~d}$ of curing. Measured values for the evaporable and non-evaporable water contents (per gram of ignited cement or "blended cement" powder) are provided in Figures 9 and 10, respectively. For both cement pastes without and with fly ash, Figure 9 indicates that all of the other
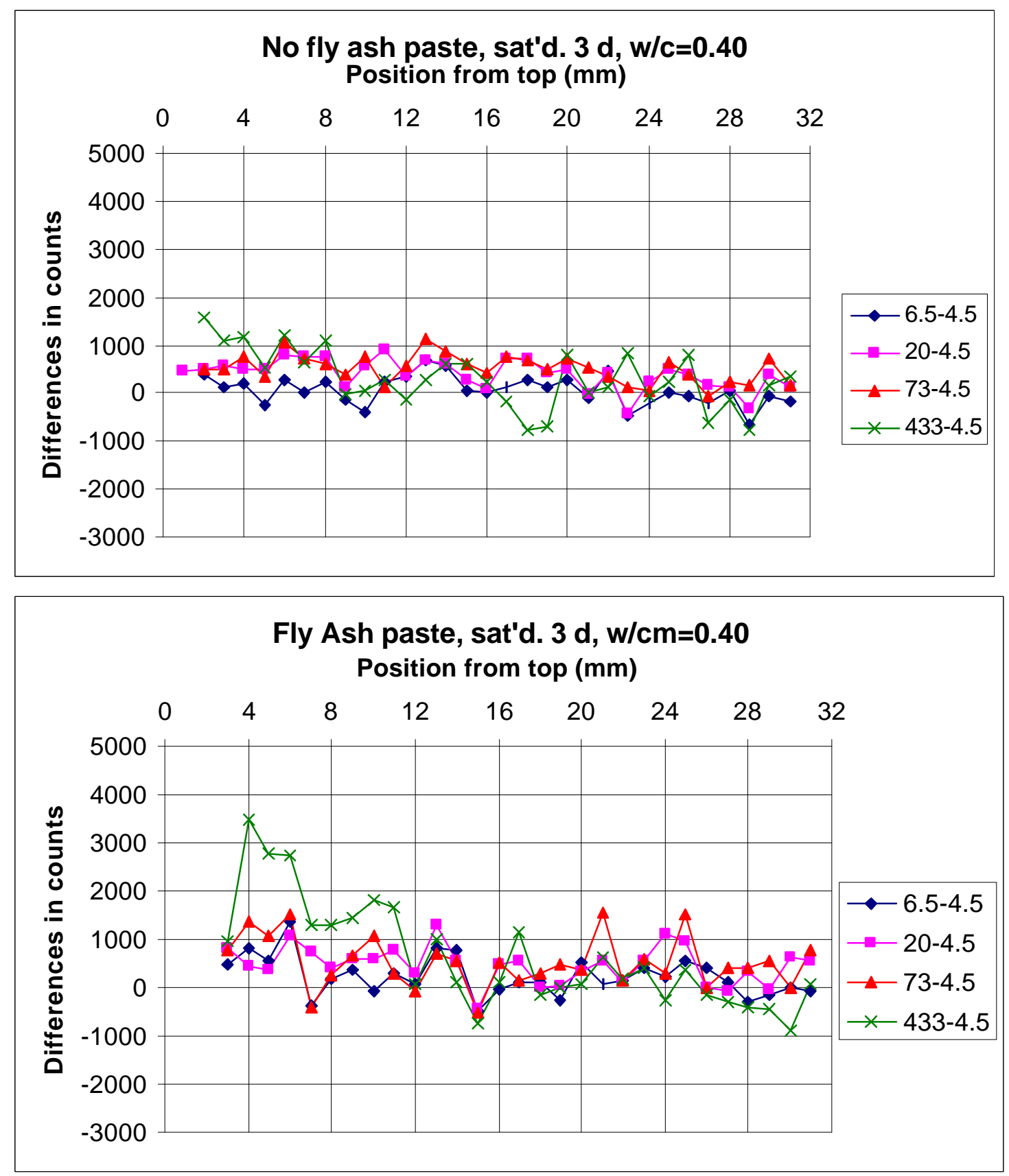

Figure 7. X-ray profiles for samples saturated for $3 \mathrm{~d}(72 \mathrm{~h})$ and then exposed to the chamber environment. All differences are relative to counts obtained for the $4.5 \mathrm{~h}$ specimens. 
investigated curing regimens are inferior to the $31 \mathrm{~d}$ of sealed curing, in terms of maintaining a high evaporable water content within the cement paste specimens, which is in direct agreement with the mass loss measurements provided in Figure 3. On a per gram of ignited powder (cement + fly ash) basis, the specimens with fly ash are consistently observed to have a lower evaporable water content, once again in agreement with the mass loss results in Figure 3. Consistent with the measured penetration depths
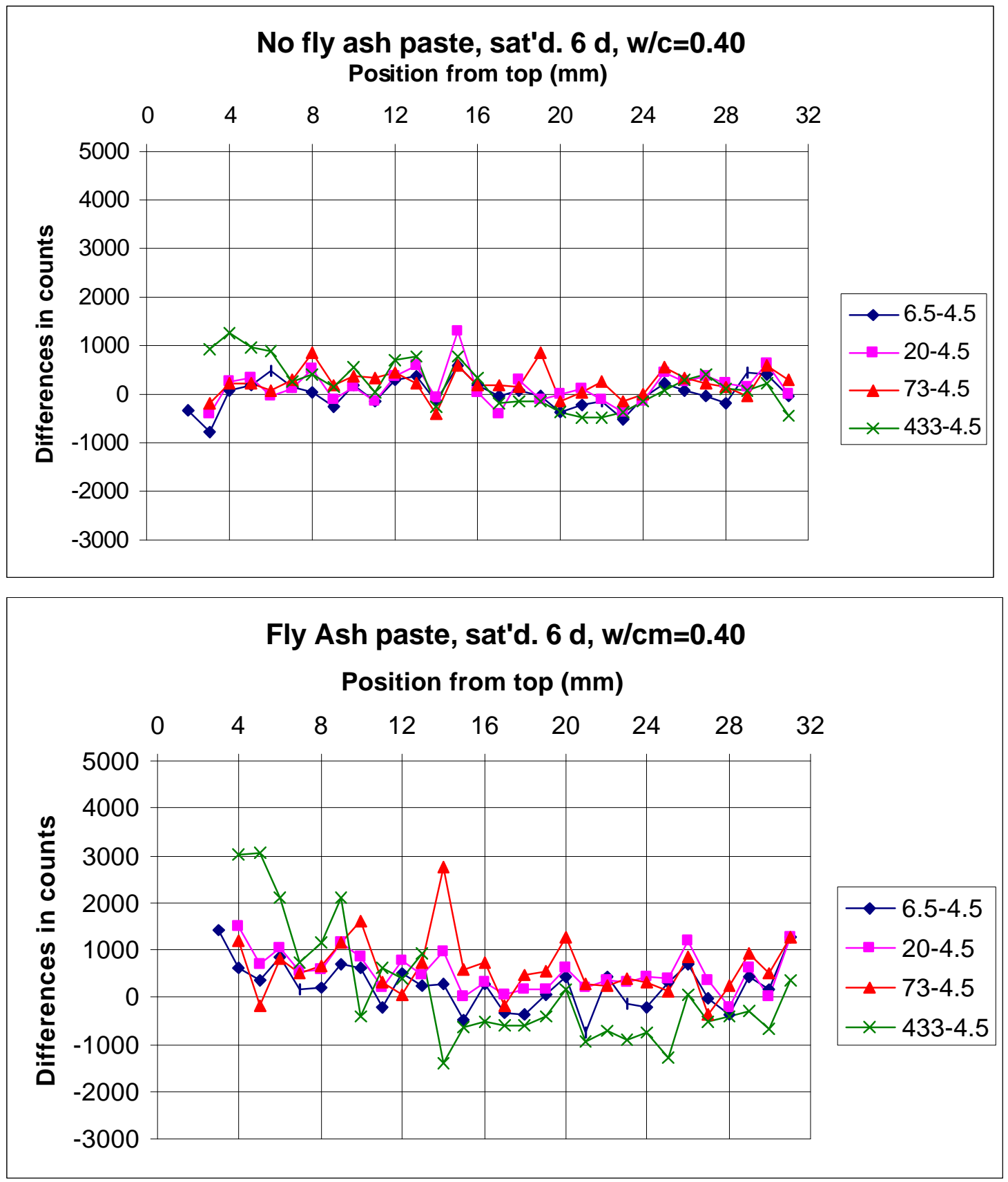

Figure 8. X-ray profiles for samples saturated for $6 \mathrm{~d}(144 \mathrm{~h})$ and then exposed to the chamber environment. All differences are relative to counts obtained for the $4.5 \mathrm{~h}$ specimens. 
of the drying fronts, the top $10 \mathrm{~mm}$ section of each specimen is observed to have a significantly lower evaporable water content than the remaining bottom section.

Unfortunately, for blended cements with pozzolans, the non-evaporable water content is not a direct measure of cement hydration (or fly ash reactivity), due to water consumption/ release during the pozzolanic reaction between fly ash and cement. This effect has been well documented for the case of the similar pozzolanic reaction that occurs when silica fume is added to cement. ${ }^{11,12}$ While this, along with differences in the Blaine finenesses of the two cements, eliminates a direct comparison between the results
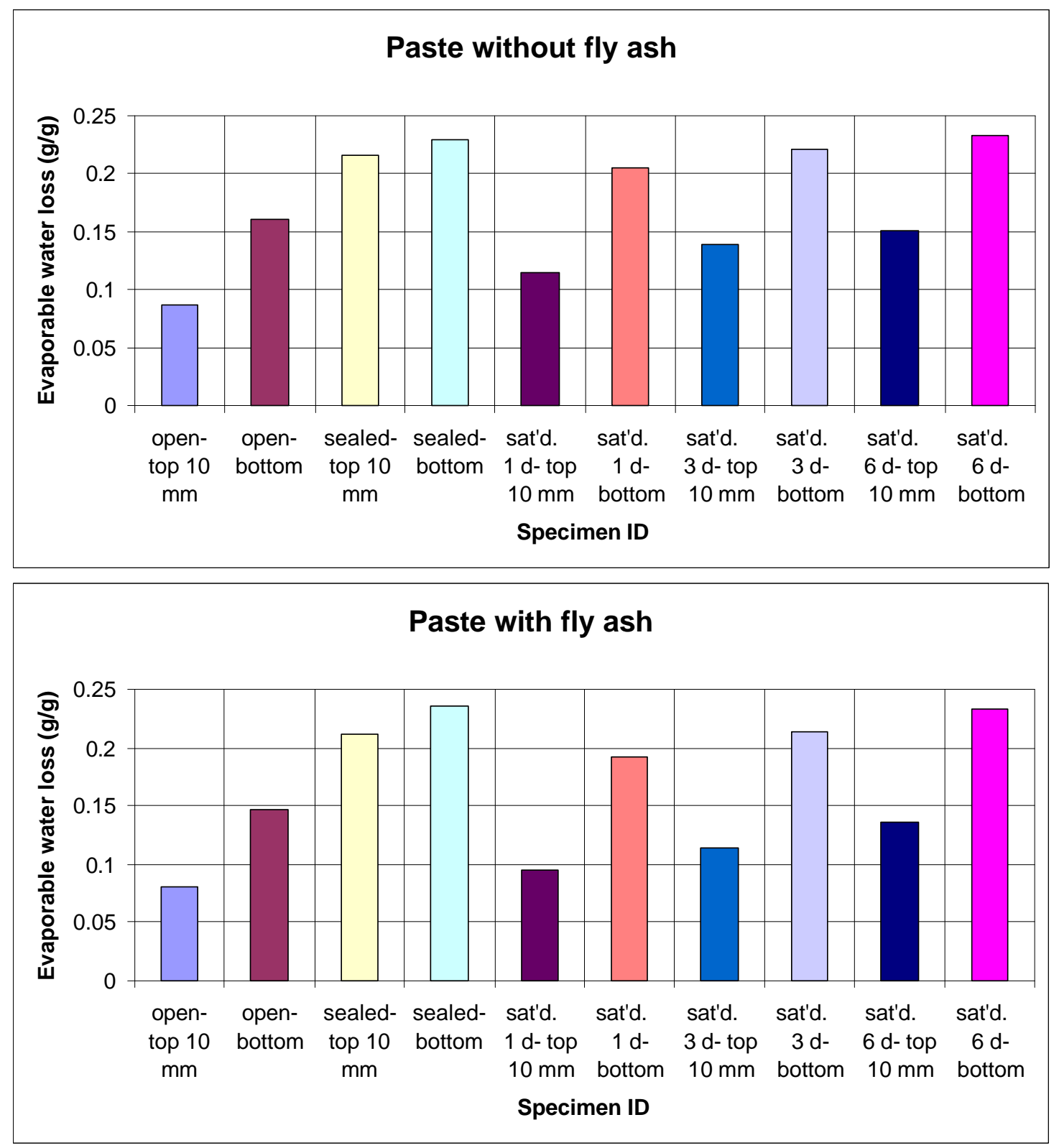

Figure 9. Evaporable water loss (g water/g ignited powder) for top and bottom sections of cement pastes without and with fly ash, exposed to various curing conditions. 
in Figure 10 for pastes without and with fly ash, one can still independently examine their individual curing sensitivity. For example, the non-evaporable water contents of the bottom sections of the pastes without fly ash indicate that both $3 \mathrm{~d}$ and $6 \mathrm{~d}$ of saturated curing (followed by drying) is slightly superior to sealed curing. For the specimens with fly ash substitution, $3 \mathrm{~d}$ or $6 \mathrm{~d}$ of saturated curing provides results that are equivalent to those achieved by sealed curing, again indicating the increased sensitivity to curing of this fly ash blended cement.
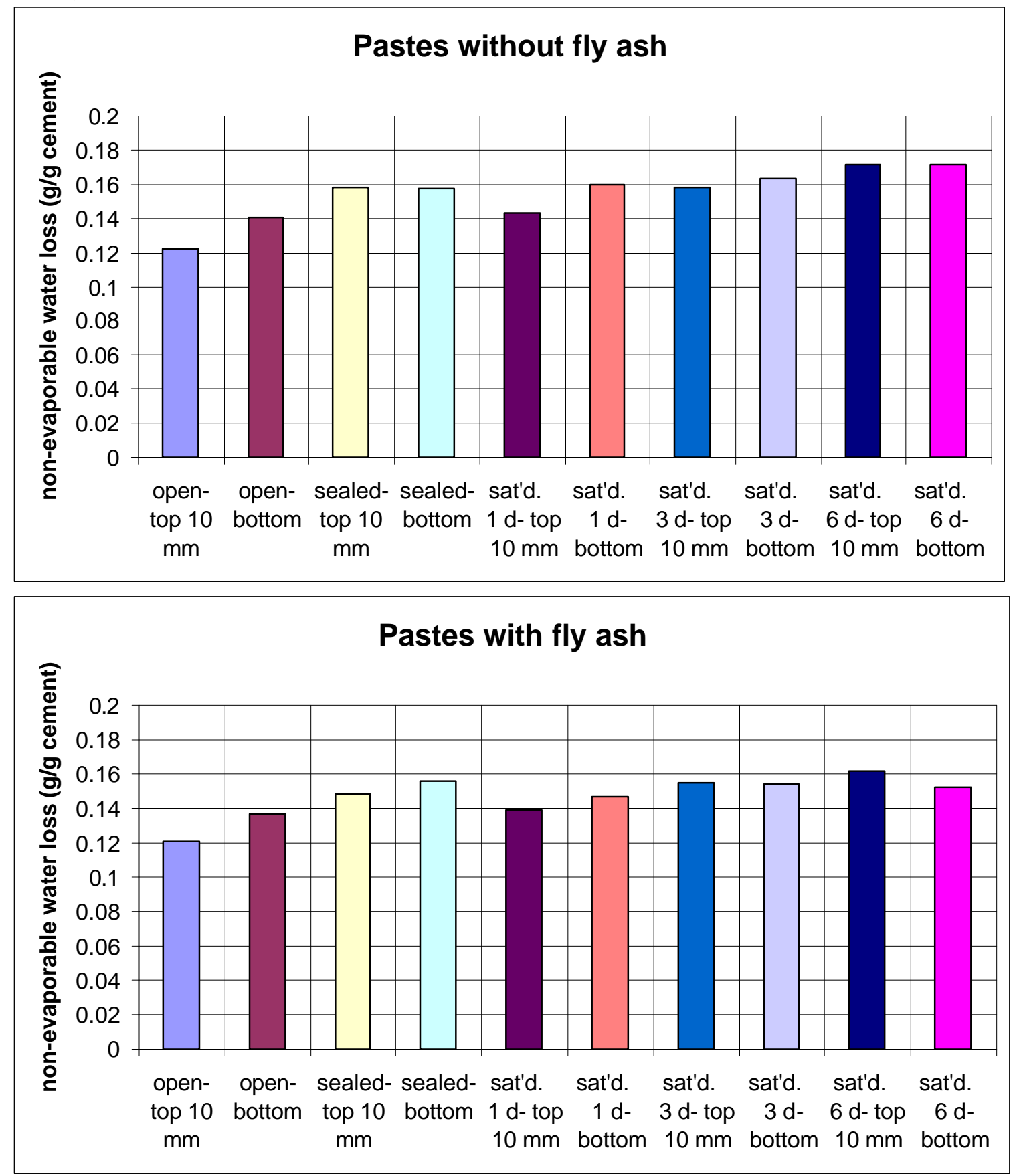

Figure 10. Non-evaporable water loss (g water/g ignited powder) for top and bottom sections of cement pastes without and with fly ash, exposed to various curing conditions. 


\section{Discussion}

The above results are preliminary in nature and many additional complexities must be considered before extrapolating them to field performance. While this study was conducted under isothermal conditions, nearly all field concrete experiences a range (and diurnal cycle) of curing temperatures. For many field conditions, elevated early-age temperatures are produced by the heat of hydration of the cementitious materials. Because the activation energy of fly ash reactions can be about double ${ }^{13}$ that of cement hydration (40 kJ/mol being typical for an ASTM Type I portland cement) ${ }^{14}$, curing temperatures can have an extremely significant influence on fly ash reactivity and its pozzolanic reaction with calcium hydroxide during the first days of hydration. The water loss/gain properties of mortars and concretes may also be different than those of the cement paste specimens explored in this study due to the presence of the aggregates and their surrounding interfacial transition zones.

This preliminary study has been conducted at only a single w/cm of 0.40 . For lower $\mathrm{w} / \mathrm{cm}$ ratios, it would be expected that the capillary pores will close off (depercolate) early in the hydration process, ${ }^{2,4}$ minimizing the ingress of needed curing water from the external environment. In these systems, due to its lower initial reactivity, the fly ash may end up acting more as an inert reinforcing filler, as the more reactive cement may consume all of the locally available curing water, with little or none remaining for the later age fly ash reactions. One possible solution to this problem for low w/cm concretes is the application of so-called "internal curing", via the addition of saturated low-density fine aggregates or superabsorbent (water-absorbing) polymer particles. ${ }^{15}$

\section{$5 \quad$ Summary and Conclusions}

Preliminary studies were conducted to examine the sensitivity of portland and blended cement pastes, prepared with a w/cm $=0.40$, to curing conditions. Small specimens of the two pastes were cast into cuvettes and exposed to five different curing conditions. Sensitivity to curing was characterized by bulk mass (water loss) measurements, local water loss inferred from X-ray absorption measurements, and quantification of the evaporable and non-evaporable water contents achieved following $31 \mathrm{~d}$ of total curing.

The following conclusions can be drawn from this preliminary study:

1) Cement pastes with fly ash additions are more sensitive to curing than those without, most likely due to a decrease in initial reaction rates.

2) X-ray absorption drying profile measurements are consistent with bulk measurements of water mass loss and provide detailed information on the depth of penetration of the drying front. This is of practical significance for field concrete, where this depth will correspond to a layer of concrete whose properties may be partially compromised by improper curing conditions. 


\section{Acknowledgements}

The author would like to thank Dr. Xiuping Feng and Mr. Paul Stutzman of NIST/BFRL for assistance in obtaining the SEM/X-ray composite images provided in Figures 1 and 2. Funding for this preliminary study was provided by the NIST HYPERCON-Partnership for High-Performance Concrete Technology (PHPCT) program. 


\section{References}

1) Meeks, K.W., and Carino, N.J., "Curing of High-Performance Concrete: Report of the State-of-the-Art," NISTIR 6295, U.S. Department of Commerce, March 1999.

2) Powers. T.C., "Capillary Continuity or Discontinuity in Cement Pastes," PCA Bulletin, No. 10, 2-12, 1959.

3) Powers, T.C., "A Discussion of Cement Hydration in Relation to the Curing of Concrete," Proc. of the Highway Research Board, 27, 178-188, 1947.

4) Bentz, D.P., and Garboczi, E.J., "Percolation of Phases in a Three-Dimensional Cement Paste Microstructural Model," Cement and Concrete Research, 21, 324-344, 1991.

5) Hansen, K.K., Jensen, S.K., Gerward, L., and Singh, K., "Dual-energy X-ray Absorptiometry for the Simultaneous Determination of Density and Moisture Content in Porous Structural Materials," in: Proc. of the $5^{\text {th }}$ Symposium on Building Physics in the Nordic Countries, Gothenburg, Sweden, Vol. 1, 281-288, 1999.

6) Bentz, D.P., and Hansen, K.K., "Preliminary Observations of Water Movement in Cement Pastes During Curing Using X-ray Absorption," Cement and Concrete Research, 30, 1157-1168, 2000.

7) Bentz, D.P., Geiker, M.R., and Hansen, K.K., "Shrinkage-reducing Admixtures and Early-age Desiccation in Cement Pastes and Mortars," Cement and Concrete Research, 31, 1075-1085, 2001.

8) Taylor, B.N., and Kuyatt, C.E., "Guidelines for Evaluating and Expressing the Uncertainty of NIST Measurement Results," NIST Technical Note No. 1297, U.S. Department of Commerce, September 1994.

9) Bentz, D.P., "Three-Dimensional Computer Simulation of Portland Cement Hydration and Microstructure Development," Journal of the American Ceramic Society, 80 (1), 3-21, 1997.

10) Taylor, H.F.W., Cement Chemistry (Thomas Telford, London, 1997).

11) Yogendran, V., Langan, B.W., and Ward, M.A., "Hydration of Cement and Silica Fume Paste," Cement and Concrete Research, 21 (5), 691-708, 1991.

12) Zhang, M.-H., and Gjorv, O.E., "Effect of Silica Fume on Cement Hydration in Low Porosity Cement Pastes," Cement and Concrete Research, 21 (5), 800-808, 1991.

13) Bentz, D.P., and Remond, S. "Incorporation of Fly Ash into a 3-D Cement Hydration Microstructure Model," NISTIR 6050, U.S. Department of Commerce, August 1997.

14) ASTM C 1074, ASTM Annual Book of Standards, Vol. 04.02 Concrete and Aggregates, 2000.

15) Bentz, D.P., Geiker, M.R., and Jensen, O.M., "On the Mitigation of Early Age Cracking," in Proceedings of Self-Desiccation and Its Importance in Concrete Technology III, Eds. B. Persson and G. Fagerlund, Lund, Sweden, June 2002. 